\title{
Perceptual learning in pigeons: Decreased ability to discriminate samples mapped onto the same comparison in many-to-one matching
}

\author{
DAREN H. KAISER and LOU M. SHERBURNE \\ University of Kentucky, Lexington, Kentucky \\ JANICE N. STEIRN \\ Georgia Southern University, Statesboro, Georgia \\ and \\ THOMAS R. ZENTALL \\ University of Kentucky, Lexington, Kentucky
}

\begin{abstract}
Humans often treat two stimuli that are associated with a common response as similar in other contexts. They do so presumably because those stimuli become conceptually or perceptually more similar to each other (perceptual learning). An analogous phenomenon may occur in pigeons when they are trained with a matching-to-sample procedure in which more than one sample is mapped onto the same comparison. In the present research, pigeons were trained to select one comparison following either of two samples $\left(\mathrm{S}_{1}\right.$ or $\left.\mathrm{S}_{2}\right)$ and to select the other comparison following either of two different samples $\left(S_{3}\right.$ or $\left.S_{4}\right)$. When the samples were then presented as positive and negative stimuli in a simple successive discrimination, samples that had been associated with the same comparison during original training (e.g., $S_{1}$ vs. $S_{2}$ ) were more difficult to discriminate than were samples that had been associated with different comparisons (e.g., $S_{1}$ vs. $S_{3}$ ). Thus, it appears that perceptual learning occurs in pigeons as well.
\end{abstract}

It is more difficult for humans to learn to discriminate between stimuli that have been given the same label than it is for them to discriminate between stimuli given different labels (Reese, 1972). This finding is an example of what has been termed perceptual learning (Epstein, 1967). Reese, for example, asked children to apply the same verbal label to two nonsense stimuli, $\mathrm{A}$ and $\mathrm{B}$, and a different verbal label to nonsense stimulus $C$. When he then asked these children to learn new motor responses to the stimuli, he found that if different motor responses were required to $A$ and $B$ learning was slower than if different responses were required to $A$ and $C$.

In some cases, children appear to treat arbitrary stimuli to which they have been trained to respond with the same label in one context as if they were similar in another context (Jeffrey, 1953). Children were first trained to make the same response (verbal or motor) to two stimuli ( $\mathrm{A}$ and $\mathrm{B}$ ) and a different response to a third stimulus (C). They were then trained to make new responses to $A$ (push a lever) and $C$ (pull a lever). When the children were tested with stimulus B in the presence of the lever, they tended to push the lever, as they had learned to do in re-

This research was supported by National Science Foundation Grant BNS-9019080 and National Institute of Mental Health Grant MH-45979. Correspondence concerning this article should be addressed to T. R. Zentall, Department of Psychology, University of Kentucky, Lexington, KY 40506 (e-mail: zentall@pop.uky.edu). sponse to A. Apparently, the untrained stimulus evoked the same response as its commonly labeled counterpart (see also Eisman, 1955).

Similar findings have been reported with Pavlovian conditioning procedures. Using a conditioned eyeblink procedure, Grice and his associates (Grice \& Davis, 1958, 1960; Grice \& Hunter, 1963) required humans to make a common motor or verbal response in the presence of two stimuli, one a positive conditioned stimulus ( $\mathrm{CS}+$ ) associated with an air puff and the other a negative conditioned stimulus (CS-) associated with the absence of an air puff, and to make a different response to a second CS-. It was found that the participants produced more eyeblinks in response to the first CS - than to the second. These findings indicate the generality of transfer effects found with humans that may occur because commonly labeled stimuli are more difficult to discriminate.

A finding that is in many ways analogous to the perceptual learning results reported in the human literature has been found using many-to-one matching-to-sample with pigeons. In matching to sample, choice of one of two comparison stimuli is reinforced, depending on which one of two initial stimuli (samples) was presented. In the manyto-one version of this task, each of two different samples signals that responses to the same comparison will be reinforced while two additional samples signal that responses to the other comparison are correct (Urcuioli, Zentall, Jackson-Smith, \& Steirn, 1989). Urcuioli et al. 
trained pigeons on many-to-one matching to sample in which red-hue and vertical-line samples were associated with the choice of one correct comparison (vertical lines) and green-hue and horizontal-line samples were associated with the choice of the other comparison (horizontal lines). Urcuioli et al. hypothesized that samples that were associated with a common comparison would be represented similarly (or would be commonly coded) by the pigeons. To test this hypothesis, after acquisition of manyto-one matching to sample, the pigeons were trained to associate the hue samples with new comparisons. The red sample was now associated with the choice of a circleshape comparison, the green sample, with the choice of a dot-shape comparison. The pigeons were then tested with the line samples and the circle/dot comparisons. The similar representation of samples associated with common comparisons was demonstrated by a generally high level of positive transfer on test trials (the pigeons chose circle following presentation of vertical samples and dot following presentation of horizontal samples; see also Wasserman, DeVolder, \& Coppage, 1992). Because the samples presented during test had never been associated with these new comparisons, choice on test trials must have been mediated by common representations that emerged as a result of samples' being associated with common comparisons during original training. Thus, pigeons appear to commonly represent arbitrary stimuli that are associated with the same response much in the same way that humans commonly represent arbitrary stimuli to which they have applied common labels.

Other research has provided convergent evidence for emergent common representations by pigeons during many-to-one matching-to-sample training. For example, if, after many-to-one matching-to-sample training, one pair of samples is associated with new comparisons, as above, and delays are inserted between offset of the sample and onset of the comparisons (delayed matching), one of the remaining samples can be presented during the delay. Results indicate that relative to control performance, matching accuracy is better if the interpolated stimulus was originally associated with the same comparison as the current sample, but matching accuracy is worse if the interpolated stimulus was associated with a comparison different from that of the current sample (Zentall, Sherburne, \& Urcuioli, 1993).

If many-to-one matching-to-sample training does, in fact, result in the common coding of samples associated with the same comparison, then it should also result in a decrease in the ability to discriminate those samples. Evidence for such loss of discriminability should be detectable using a task that requires discrimination of the presumed commonly represented samples. The samples that have been associated with the same comparison should be harder to discriminate from each other than the samples that have been associated with a different comparison.

In the present study, an attempt was made to test this hypothesis. Pigeons first received many-to-one matchingto-sample training similar to that of previous research (e.g., Urcuioli et al., 1989). They were then tested with a simple successive discrimination involving the samples from original training. For half of the pigeons, the successive discrimination was consistent with the presumed common representations that occurred during many-to-one matching-to-sample training. That is, the two positive stimuli were previously associated with one comparison and the two negative stimuli were previously associated with the other comparison. For the remaining pigeons, the successive discrimination was inconsistent with the presumed common representations that had occurred during original training. That is, the positive stimuli were previously associated with different comparisons, and so too were the negative stimuli. If, during original many-to-one matching-to-sample training, samples associated with the same comparison became harder to discriminate because they were commonly represented, then pigeons should acquire the successive discrimination faster when the positive and negative stimulus sets are consistent with those presumed to be common representations.

It was also hypothesized that emergent common representation of samples associated with the same comparison might be facilitated if, during training, the pigeons were exposed to delays (between the sample offset and comparison onset). It was reasoned that difficulty in remembering samples over the delay might encourage, or strengthen, the common representation of samples associated with the same comparison (see Steirn, Zentall, \& Sherburne, 1993).

\section{METHOD}

\section{Subjects}

Sixteen White Carneaux pigeons purchased from the Palmetto Pigeon Plant (Sumter, SC) served as subjects. All pigeons had had prior experience pecking lit response keys. The pigeons were individually housed in wire cages with continuous access to water and grit, and were maintained at $75 \%-80 \%$ of their free-feeding weights throughout the experiment. The colony room was maintained on a 12:12-h light:dark cycle.

\section{Apparatus}

The experiment was conducted in a sound-attenuated three-responsekey operant chamber (LVE/BRS, Laurel, MD). The chamber measured $35 \mathrm{~cm}$ high $\times 30.5 \mathrm{~cm}$ wide $\times 35 \mathrm{~cm}$ across the response panel, The three round pecking keys were $3 \mathrm{~cm}$ in diameter and were mounted side by side, $3.5 \mathrm{~cm}$ apart edge to edge, with the bottom of each key $19 \mathrm{~cm}$ from the floor of the chamber. Mounted behind each pecking key was a 12-stimulus in-line projector (Industrial Electronics Engineering, Series 10, Van Nuys, CA, with General Electric No. 1820 lamps). The projector for the center key projected red (R) or green (G) hues (Kodak Wratten filters Nos. 26 and 60, respectively), and white (W, no filter). Three white vertical $(\mathrm{V})$ or horizontal $(\mathrm{H})$ lines on a black background (each line was $13 \mathrm{~mm}$ long $\times 3 \mathrm{~mm}$ wide, with the lines separated by $3 \mathrm{~mm}$ ) could also be projected on the center key. The projectors for the side keys projected a white line-drawn circle (C, 16-mm outside diameter, 13-mm inside diameter) or a white dot (D, 5-mm diameter) on a black background. Access to a rear-mounted grain feeder filled with Purina Pro Grains was provided through a horizontally centered opening in the response panel $(6.0 \times 5.0 \mathrm{~cm})$. The bottom edge of the feeder was located $7 \mathrm{~cm}$ from the floor of the chamber. A feeder lamp was illuminated whenever the grain feeder was operated. A shielded houselight, located on the ceiling of the chamber at the midline of and $13 \mathrm{~cm}$ from the response panel, provided general chamber illumination. White noise (at $72 \mathrm{~dB}$ ) and an exhaust fan provided masking noise. The experiment was controlled by a microcomputer located in an adjacent room. 


\section{Procedure}

Many-to-one matching-to-sample training. Because all of the birds had had previous experience pecking lit keys, they were immediately placed on many-to-one matching-to-sample training with 0 -sec delays between the offset of sample and onset of comparisons. Each trial began with the presentation of $\mathrm{W}$ as a warning stimulus on the center key, and a single peck resulted in a 6-sec presentation of $\mathrm{R}, \mathrm{G}, \mathrm{V}$, or $\mathrm{H}$ on the center key. Immediately following offset of the sample, comparisons (C and D) were presented on each of the side keys. Whether $C$ or $D$ was presented on the left or right key was randomized with the restriction that they could not occur on the same key for more than three consecutive trials. A single peck to $C$ resulted in a 1.5 -sec reinforcement following $R$ or $V$ samples, as did a single peck to $D$ following $G$ or $H$ samples. Incorrect choices resulted in a 1.5-sec time-out. All trials ended in a 10-sec intertrial interval (ITI) that included the reinforcement or timeout. The houselight was lit during the ITI and at all other times was dark. The birds received 96 trials per session, and sessions were conducted 6 days a week. The birds were trained in this manner until they reached a criterion of $90 \%$ correct (or higher) for 2 consecutive days on both huesample and line-sample trials. Criterion included the following provision: If the pigeons reached the 2-days-at- $90 \%$ criterion on one dimension (hue or line) before reaching criterion on the other dimension, they were required to maintain a level of at least $83 \%$ correct on the first dimension when they reached the $90 \%$ criterion for the second; otherwise, training continued until they did. Following criterion performance, half of the pigeons received mixed-delay training $(0-, 1-, 2-$, and 4-sec delays) for 20 sessions. The delay was inserted between the offset of the sample and the onset of the comparisons. The remaining pigeons were overtrained with 0 -sec delays for 20 sessions. If, after these 20 sessions of additional training, a pigeon's matching accuracy at the 0-sec delay was below $83 \%$ correct, training continued until that criterion was met.

Testing. All pigeons were then trained on a successive discrimination task involving each of the four samples from original training. Immediately following a single peck to a W warning stimulus presented on the center key, the stimuli were presented on the center key for $6 \mathrm{sec}$ The stimuli designated as positive were followed by a $1.5-\mathrm{sec}$ reinforcement and a 10-sec ITI; the stimuli designated as negative were followed by a $1.5-\mathrm{sec}$ time-out and a $10-\mathrm{sec}$ ITI. Half of the pigeons from the overtraining and delay-training groups were trained to discriminate between samples that had been paired with different comparisons (consistently transferred group $=\mathrm{R}+, \mathrm{V}+, \mathrm{G}-, \mathrm{H}-$, or $\mathrm{R}-, \mathrm{V}-$, $\mathrm{G}+, \mathrm{H}+$ ). The remaining birds were trained to discriminate between samples that had previously been paired with the same comparison (inconsistently transferred group $=\mathrm{R}+, \mathrm{V}-, \mathrm{G}-, \mathrm{H}+$, or $\mathrm{R}-, \mathrm{V}+, \mathrm{G}+$, $\mathrm{H}-$ ). The design of the experiment appears in Table 1 . The performance measure for each test session was a discrimination ratio obtained by dividing the total number of pecks to the two stimuli designated as positive by the total number of pecks to all four stimuli. All pigeons were trained to a criterion of two sessions with a discrimination ratio of .90 or better.

Table 1

Design of Experiment

\begin{tabular}{ccc}
\hline & \multicolumn{2}{c}{ Test } \\
\cline { 2 - 3 } $\begin{array}{c}\text { Original Training } \\
\text { MTO MTS }\end{array}$ & Consistent & Inconsistent \\
\hline $\mathrm{R} \rightarrow \mathrm{C}$ & $\mathrm{R}+$ & $\mathrm{R}+$ \\
$\mathrm{V} \rightarrow \mathrm{C}$ & $\mathrm{V}+$ & $\mathrm{V}-$ \\
$\mathrm{G} \rightarrow \mathrm{D}$ & $\mathrm{G}-$ & $\mathrm{G}-$ \\
$\mathrm{H} \rightarrow \mathrm{D}$ & $\mathrm{H}-$ & $\mathrm{H}+$ \\
\hline
\end{tabular}

Note--MTO MTS = many-to-one matching-to-sample, $\mathrm{R}=\mathrm{red}, \mathrm{G}=$ green, $\mathrm{V}=$ vertical, $\mathrm{H}=$ horizontal, $\mathrm{C}=$ circle, $\mathrm{D}=$ dot, “+” = reinforcement following 6-sec duration stimulus, "-" = nonreinforcement following 6-sec duration stimulus. Test conditions are consistent or inconsistent with the presumed common representations acquired during original training. Only one of the two consistent and inconsistent groups is shown. Conditions for the groups not shown can be determined by changing the signs associated with each of the stimuli shown. Following original training, half of the animals received overtraining with no delays, while the other half received training with mixed delays

\section{RESULTS}

One bird did not acquire the many-to-one matching-tosample task and was dropped from the experiment. Another bird was dropped because it became sick during testing and would not complete test sessions even when left in the chamber overnight. A probability value of .05 was adopted as the level of significance for all analyses.

A one-way analysis of variance (ANOVA) performed on acquisition sessions to criterion of many-to-one matching to sample, with training group (delay training vs. overtraining) and test group (consistent vs. inconsistent) as factors, revealed no significant differences $[F(3,10)<1]$. Also, terminal performance on 0 -sec delay trials, the session before transfer to the simple successive discrimination task, was analyzed with a two-way ANOVA, and it revealed no significant effects of delay training versus overtraining conditions $[F(1,10)<1]$, transfer condition assigned $[F(1,10)<1]$, or the interaction between them $[F(1,10)=2.64]$.

Transfer data were collected from 14 pigeons ( 7 pigeons consistently transferred and 7 inconsistently transferred). When the data were collapsed across delay training versus overtraining, the consistently transferred group acquired the successive discrimination in a mean of 8.0 $(S E=.85)$ sessions, while the inconsistently transferred group acquired the successive discrimination in a mean of $31.3(S E=8.48)$ sessions. A two-way ANOVA was performed with consistent versus inconsistent transfer and delay training versus overtraining as factors. The main effect of consistent versus inconsistent transfer was significant $[F(1,10)=6.74]$, but not the effect of delay training versus overtraining $[F(1,10)=1.13]$ or the interaction $[F(1,10)=1.28]$. Because the variability in sessions to criterion was so much greater in the inconsistently transferred group, a log transformation was performed on the data. A one-way analysis performed on the transformed data confirmed that the consistently transferred group $(M=.89, S E=.04)$ acquired the successive discrimination significantly faster than the inconsistently transferred group $[M=1.33, S E=.18 ; F(1,12)=5.72]$.

\section{DISCUSSION}

The results indicate that for pigeons, many-to-one matching-tosample training can result in a generally decreased ability to discriminate between stimuli that are associated with the same comparison. Presumably the common representations that were formed during original many-to-one matching-to-sample training made it more difficult for the pigeons to discriminate between stimuli associated with the same comparison than between stimuli that were associated with different comparisons.

If one compares the rates of acquisition of the successive discrimination from the present experiment with those of pigeons that have had no prior matching training, it suggests that the present results can be attributed to negative transfer or decreased ability to discriminate in the inconsistent condition rather than to positive transfer in the consistent condition (due to acquired distinctiveness of cues; e.g., Lawrence, 1949). Zentall, Steirn, Sherburne, and Urcuioli (1991) reported initial acquisition of a simple successive discrimination involving two $\mathrm{S}+\mathrm{s}$ (e.g., $\mathrm{R}$ and $\mathrm{V}$ ) and two $\mathrm{S}-\mathrm{s}$ (e.g., G 
and $\mathrm{H}$ ), under conditions similar to those of the present experiment, in an average of 5.1 sessions. In the present experiment, the consistent group took about 8 sessions to learn the simple successive discrimination, whereas the inconsistent group, which was required to discriminate between presumably commonly represented stimuli, took about 31 sessions to learn the discrimination. Although the procedures were not exactly the same, comparison of the order of magnitude of the sessions-to-criterion measure between these two experiments suggests that the presumably commonly represented stimuli in the present experiment were particularly hard to discriminate rather than that the distinctively coded stimuli were easier to discriminate.

We originally hypothesized that delay training might facilitate the formation of common representations, leading to a reduction of discriminability of stimuli within classes. It did not. It is possible, however, that original training plus overtraining was sufficient to maximize the formation of common representations and that delay training contributed little in addition.

In the introduction to this article, we used the term perceptual learning to refer to the effect found in humans, analogous to that reported here. One could argue, however, that the slow rate of acquisition of the successive discrimination by pigeons in the inconsistent group does not actually represent a failure to discriminate in the perceptual sense of the term, but rather represents the inability of the pigeons to attach differential responses to two sample stimuli associated with the same comparison. Thus, many-to-one delayed matching training may not cause samples to be perceptually more similar to each other. Rather, it may be that the similarity of comparison response acquired during delayed matching training results in a conceptual "set" to treat those two samples similarly in other contexts as well (i.e., successive discriminations). Neither the present experiment nor the traditional perceptual learning experiments on which the present experiment is based distinguish between these two mechanisms.

The similarities in procedures and findings that have been shown in the human perceptual learning literature and animal common coding literature suggest that common mechanisms may be involved. Transfer effects that occur between stimuli that share the same verbal label in humans may be related to similar learning processes that produce the transfer effects that have been shown in pigeons when stimuli are associated with common outcomes. The present results add to growing literature that suggests a similarity between humans and other animais in conceptual and perceptual processing (see, e.g., Peterson, 1984; Schusterman \& Kastak, 1993; Vaughan, 1988; Yamamoto \& Asano, 1995; Zentall \& Smeets, 1996).

Finally, the present results also have implications for the role of language in perceptual learning. It has been proposed by some (see Horne \& Lowe, 1996) that language is a prerequisite for emergent behavior of the type typically shown in human perceptual learning experiments. The ability of a nonverbal organism to show evidence of transfer effects analogous to that of human transfer effects, suggests that this hypothesis is incorrect. In fact, it is more likely that common representations that result in a decreased ability to discriminate are necessary prerequisites for the equivalence relationships that must develop between arbitrary stimuli (i.e., written and spoken words) and the events that they represent (i.e., meaning) in the acquisition of human language.

\section{REFERENCES}

Eisman, B. S. (1955). Attitude formation: The development of a colour preference response through mediated generalization. Journal of $A b$ normal \& Social Psychology, 50, 321-326.

EPSTEIN, W. (1967). Varieties of perceptual learning. New York: McGraw-Hill.

GRICE, G. R., \& DAVIs, J. D. (1958). Mediated stimulus equivalence and distinctiveness in human conditioning. Journal of Experimental Psychology, 55, 565-571.

Grice, G. R., \& DAVIS, J. D. (1960). Effects of concurrent responses on the evocation and generalization of the conditioned eyeblink. Journal of Experimental Psychology, 59, 391-395.

GricE, G. R., \& HUNTER, J. J. (1963). Response mediation of the conditioned eyeblink response. Journal of Experimental Psychology, 66, 338-346.

HORNE, P. J., \& LoWE, C. F. (1996). On the origins of naming and other symbolic behavior. Journal of the Experimental Analysis of Behavior, 65, 185-241.

JEFFREY, W. E. (1953). The effects of verbal and nonverbal responses in mediating an instrumental act. Journal of Experimental Psychology, $45,327-333$.

LAWRENCE, D. H. (1949). Acquired distinctiveness of cues: I. Transfer between discriminations on the basis of familiarity with the stimulus. Journal of Experimental Psychology, 39, 770-784.

Peterson, G. B. (1984). How expectancies guide behavior. In H. L. Roitblat, T. G. Bever, \& H. S. Terrace (Eds.), Animal cognition (pp. 135147). Hillsdale, NJ: Erlbaum.

REESE, H. W. (1972). Acquired distinctiveness and equivalence of cues in young children. Journal of Experimental Child Psychology, 13, 171-182.

Schusterman, R. J., \& KASTAK, D. (1993). A California sea lion ( $Z a-$ lophus californianus) is capable of forming equivalence relations. Psychological Record, 43, 823-839.

Steirn, J. N., Zentall, T. R., \& SherbuRne, L. M. (1993). Representation strength in pigeon short-term memory: Effect of delay training. Animal Learning \& Behavior, 21, 113-119.

URCuioli, P. J., Zentall, T. R., Jackson-Smith, P., \& Steirn, J. N. (1989). Evidence for common coding in many-to-one matching: Retention, intertrial interference, and transfer. Journal of Experimental Psychology: Animal Behavior Processes, 15, 264-273.

VAUGHAN, W., JR. (1988). Formation of equivalence sets in pigeons. Journal of Experimental Psychology: Animal Behavior Processes, 14, 3642

Wasserman, E. A., DeVolder, C. L., \& Coppage, D. J. (1992). Nonsimilarity-based conceptualization. Psychological Science, 3, 374-379.

Yamamoto, J., \& Asano, T. (1995). Stimulus equivalence in a chimpanzee (Pan troglodytes). Psychological Record, 45, 3-21.

Zentall, T. R., Sherburne, L. M., \& Urcuioli, P. J. (1993). Common coding by pigeons in a many-to-one delayed matching task as evidenced by facilitation and interference effects. Animal Learning \& Behavior, 21, 233-237.

Zentall, T. R., \& SMEETS, P. M. (EDs.) (1996). Stimulus class formation in humans and animals. Amsterdam: Elsevier.

Zentall, T. R., Steirn, J. N., Sherburne, L. M., \& Urcuioli P. J. (1991). Common coding in pigeons assessed through partial versus total reversals of many-to-one conditional and simple discriminations. Journal of Experimental Psychology: Animal Behavior Processes, $17,194-201$.

(Manuscript received October 21, 1996; revision accepted for publication February 18, 1997.) 